\title{
A Instabilidade no Universo Ficcional de ESSA TeRRA, DE ANTÔNIO TORRES
}

Rogerio Gustavo GONÇALVES*

\section{RESUMO}

O artigo aborda a composição formal do romance Essa terra, de Antônio Torres, buscando evidenciar o caráter instável das categorias narrativas de tempo e espaço como reflexo da condição de desterritorialização dos personagens e de sua consequente fragmentação identitária. O estudo procura também mostrar como a pluralidade de vozes, responsável por essa relativização espaço-temporal, possibilita uma visão multifacetada da temática abordada a migração -, concedendo um caráter aberto à obra, sem a apresentação de uma posição conclusiva sobre as questões levantadas, de modo a estimular a reflexão do leitor.

Palavras-Chave: Antônio Torres, memória, fragmentação espaço-temporal, polifonia, identidade.

\section{OS DESLOCAMENTOS ESPAÇO-TEMPORAIS EM ESSA TERRA}

O romance Essa terra, publicado pela primeira vez em 1976, apresenta a história trágica de uma família do sertão baiano a partir da narração memorialística de um de seus integrantes, o personagem Totonhim. A trama gira em torno do episódio da morte de Nelo, irmão mais velho do narrador, que comete suicídio ao voltar para a casa da família, no pequeno vilarejo de Junco, após ter vivido 20 anos em São Paulo. Dessa maneira, o romance problematiza a situação do retirante nordestino, que procura, na fuga para as grandes capitais do Sudeste do Brasil, um meio de escapar da miséria e da seca - tema já bastante explorado, principalmente pela literatura regionalista das décadas de 1930 e 1940 -, focalizando as circunstâncias decorrentes do processo

* Graduado em Letras. Mestre em Letras. Doutor em Letras pela Universidade Estadual Paulista (UNESP), São José do Rio Preto, São Paulo, Brasil. E-mail: rogeriogstvo@yahoo.com.br. 
migratório, como as más condições de vida no cotidiano urbano e o consequente movimento de retorno à terra natal.

O desenvolvimento dos principais temas, como a migração, o atraso econômico do sertão e as relações familiares deterioradas, ocorre principalmente a partir das lembranças do narrador, cujas múltiplas associações desordenam toda a cronologia. Acompanhando os saltos da memória de Totonhim e também dos outros personagens principais, constrói-se uma espécie de narrativa interior, que se estrutura na representação de um tempo não linear, marcado por digressões e mudanças bruscas. Do processo de rememoração dos personagens procede a construção fragmentária do romance, que intercala vários momentos dispersos do passado. Jogando com vários níveis temporais, o romance apresenta-se como uma série descontínua de quadros, podendo algumas de suas cenas ser deslocadas sem prejuízo ao enredo. Repleta de lacunas, das quais algumas serão preenchidas somente aos poucos pelo narrador-personagem, quando este retorna ao desenvolvimento de episódios interrompidos, a narrativa parece projetar um tipo de leitor comprometido com o intrincado jogo romanesco - constituído por muitas idas e vindas temporais -, ao solicitar sua constante participação. A "desordem" na sequência narrativa, como tentativa de representar o mecanismo de surgimento aleatório das lembranças, acaba por exigir um esforço de memória também do leitor, que é induzido a recordar as sequências que foram suspensas e depois retomadas.

Conforme descreve Vicentini (1998, p. 51), os episódios narrados de Essa terra "cortam o tempo de um dia cravado, do meio-dia, hora do suicídio de Nelo, até a manhã seguinte, com o enterro deste e o retorno de Totonhim do hospício onde deixaria a mãe e sua ida para São Paulo". Entretanto, enquanto a ocasião da morte de Nelo compreende o tempo de um dia, o tempo ficcional do plano da memória de eventos anteriores expande-se para muito além desse curto período. Mendilow comenta sobre as várias instâncias responsáveis por estender a constituição do tempo da narrativa, relacionando alguns dos recursos que as instauram:

Quando são abrangidos períodos muito breves de tempo ficcional, deve-se lembrar, evidentemente, que essa curta estimativa é feita com base apenas em um dos planos temporais envolvidos, pois toda a vida dos protagonistas é introduzida naquele período através do 
uso de vários artifícios, como o flashback, a corrente de consciência e a troca-de-tempo (MENDILOW, 1972, p. 79).

A multiplicidade de instâncias memoriais advindas desse episódio nuclear em que Nelo comete o suicídio, também relatado a partir da memória do narrador principal, tem por consequência a multiplicidade de começos, sendo que cada um poderia aparecer num capítulo introdutório. Como resultado, parece não haver nenhum começo determinado, do qual tudo proceda em sequência, embora encontremos como um ponto "fixo", no qual os demais eventos se ancoram, essa passagem da morte de Nelo que, avançando, inicia e finaliza o romance.

Por meio de um olhar retrospectivo do narrador, o relato dos fatos se inicia do ponto em que Totonhim chega à casa dos falecidos avós, onde mora, e encontra o irmão Nelo morto na sala, pendurado no armador da rede. A partir daí, por meio das reminiscências dos personagens principais, o leitor fica sabendo o que aconteceu antes (os motivos da ida de Nelo para São Paulo e de seu retorno inesperado a Junco, a decadência financeira da família, sua desagregação e as transformações ocorridas no vilarejo) e depois desse fato. Esses acontecimentos aparecem no romance de maneira descontínua, intercalados, e a referência de tempo, neles, nem sempre é clara ou percebida de imediato. Ligado à prática de começar inmedias res, o romance, com a apresentação inicial desse plano narrativo da morte de Nelo, que figura num passado mais recente do narrador, recupera os fatos antecedentes, proporcionando o efeito de um desfecho antecipado.

Os capítulos se alternam num tempo que se move para trás e para frente, para antes e depois da morte de Nelo - apresentada no capítulo inicial do romance -, num movimento pendular, conforme sugere o próprio narrador em algumas de suas alusões à configuração temporal da narrativa, por meio de sutis imagens ou notações metalinguísticas:

Vinte anos para a frente, vinte anos para trás. E eu no meio como dois ponteiros eternamente parados, marcando sempre a metade de alguma coisa - um velho relógio de pêndulo que há muito perdeu o ritmo e o rumo das horas. Eis com me sinto e não apenas agora, agora que já sei como tudo terminou (TORRES, 2005, p. 18). 
A última frase do excerto acima, "Eis como me sinto e não apenas agora, agora que já sei como tudo terminou", revela o teor memorialístico da narração de Totonhim que, no presente da enunciação, no "agora", declara ter o conhecimento prévio do desfecho da história que irá contar. A reiteração, no decorrer do romance, da imagem do relógio de pêndulo desgovernado remete ao modo desordenado, "confuso", em que se apresentam, em sua memória, as lembranças dos fatos passados. A própria construção fragmentária da trama é uma consequência dessa aleatoriedade da memória, na qual a disposição dos curtos capítulos ou episódios, em ziguezague no tempo, apresenta-se como um quebracabeça em que é solicitada a atividade do leitor para montá-lo, para construir o tempo cronológico, linear, da fábula, no sentido do termo empregado por Tomachevski ${ }^{1}$. Desse modo, a viagem de Nelo para a capital paulista e seu retorno ao sertão, ou seja, o trajeto de ida e volta do personagem no espaço, também se projetam na constituição do tempo do romance, na disposição dos episódios.

Graças à intensa atividade mental do narrador principal, o leitor é levado de um lado para outro, de um tempo para outro, em que cada fragmento de memória, na maioria das vezes, é tratado como um presente dramático e não como um passado relativo ao evento maior da história, que é a morte de Nelo:

Primeiro neto, primeiro filho - talvez seja nisso que pense, ao fazer uma vistoria completa da casa, quarto a quarto, sala a sala. Agora está na cozinha, sentado no velho fogão de lenha, olhando sem entender o fogão a gás que eu uso e que serviu para os últimos chás de meu avô. [...]

Ele se levanta e fica de pé [...], na porta do quintal. Reclama. As flores estão morrendo. Se minha avó fosse viva, elas não estariam morrendo. Pergunta por papai (TORRES, 2005, p. 21).

Na representação da memória dos personagens, as barreiras do tempo parecem diluir-se e o passado parece convergir numa espécie de presente da narrativa. O emprego, muitas vezes, pelo narrador, dos verbos no presente do indicativo com função de pretérito, para relatar eventos passados, aproxima o leitor da cena, como se visse uma imagem focalizada por uma câmera em close-up, ou primeiro plano, ou como se fosse um espectador de uma representação teatral. Quanto 
a esta última impressão, torna-se significativa a duração exata de 24 horas do primeiro plano narrativo, referente ao suicídio de Nelo, se a relacionarmos ao fato de que as tragédias encenadas na Grécia Antiga, segundo Aristóteles, na Poética (1951, V, p. 12-16), deviam "encerrarse, tanto quanto possível, no tempo de uma única revolução do Sol ou não ultrapassá-la senão um pouco".

As relações de alternância entre as diversas linhas de ação constitutivas da história, a que Mendilow (1972, p. 205) chama de "trocade-tempo", têm, segundo este autor, a função de dar ênfase maior a um determinado episódio. No caso de Essa terra, a exposição intercalada dos fatos faz com que o episódio do suicídio de Nelo seja colocado em relevo, por ser incessantemente retomado, entre uma recordação e outra dos personagens. A justaposição de episódios avulsos sobre fatos anteriores a este também tem o mérito de retardar o desenvolvimento dessa ação principal, alimentando a expectativa do leitor. Além desse vaivém no tempo, resultante da disposição dos episódios, a imagem do relógio de pêndulo, presente no início do romance, alude à própria situação de Nelo pendurado na corda junto à parede da sala. Do mesmo modo que o corpo inerte do morto, o andamento desse plano narrativo é suspenso para dar lugar à narração do tempo da memória de Totonhim e dos outros personagens.

Em virtude da fragmentação deliberada da sequência, com montagens ou flashbacks, na forma de exposição intercalada, que levam aos cortes e às retomadas súbitas e a outros efeitos como aproximação e distanciamento, Antônio Torres mostra, com frequência, não apenas em Essa terra, mas em grande parte de sua obra, uma marcada similaridade com as técnicas temporais do cinema. Em Um cão uivando para a luaromance de estreia do autor, de 1972 -, por exemplo, que se assemelha a Essa terra quanto aos cortes ou à descontinuidade das sequências narrativas, enquanto o personagem nomeado pela inicial $\mathrm{T}$. exibe um documentário a amigos em sua casa, o narrador em terceira pessoa faz uma descrição das técnicas utilizadas nas etapas de composição do filme, o que pode ser tomado como uma referência a alguns procedimentos de construção utilizados pelo próprio romancista:

O filme era interessante. Qualquer coisa sobre os nordestinos, produzido pela TV belga. Abria com uma panorâmica da terra seca, 
rachada, enquanto, lá no fundo, ia aparecendo um carro de bois. [...] Cortava para uma série de entrevistas nos mocambos, destino de muitos dos passageiros daquele pau-de-arara. [...] Quando chega ao Rio, ponto final da história, o narrador fala em cidade do paradoxo, com otimismo de um lado (na tela, Zona Sul, corpos dourados, surf) e a miséria de outro. Corte para as favelas [...] (TORRES, 2002, p. 45).

As rupturas temporais e espaciais em Essa terra coincidem, quase sempre, com as divisões aparentes da obra em partes ou capítulos. Todavia, há vezes em que essas mudanças ocorrem no meio de um episódio, subitamente, entre uma frase e outra, dificultando a percepção do leitor:

Ela se bate contra a parede. Nunca pensei que ainda tivesse tanta força. É a lua. Lua cheia. A parede estremece. Daqui a pouco a casa desaba. Daqui a pouco estarei soterrado, debaixo das telhas. Posso fazer alguma coisa?

- Ela. Ela. Ela.

— Quem, papai? De quem o senhor está falando?

- Ela. A dona. A mãe de vocês.

- O que foi que ela fez, papai?

- Quebrou a garrafa que guardei no quarto. Era dos trabalhadores. Vou ter de pagar mais essa derrota (TORRES, 2005, p. 124).

No primeiro parágrafo desse trecho, Totonhim narra um momento de acesso de loucura da mãe, diante do filho Nelo morto, na sala da casa dos avós, enquanto o pai confecciona o caixão, no mesmo local. Essa situação remete Totonhim ao tempo em que presenciava as constantes brigas do casal, nas quais sobressaíam a fúria e a violência maternas. A partir do parágrafo seguinte, em discurso direto ("- Ela. Ela. Ela."), o diálogo que se inicia entre pai e filho já é relativo a esse passado distante, como se Totonhim se reportasse de imediato a uma das cenas presenciadas de desavença entre os pais, conforme ela surge em sua memória. Os planos temporais, às vezes, são bruscamente interrompidos e de maneira tão elíptica que se sente alguma dificuldade em identificar, à primeira leitura, o ponto exato onde se operam essas mudanças. Os retrocessos ou flashbacks iniciam ou terminam, muitas 
vezes, sem introdução ou referência à sua relação cronológica com cenas precedentes ou posteriores. Inicialmente, não se sabe o tempo a que o episódio se refere e, constantemente, também não é revelado, de imediato, quem fala, de quem se fala e a quem se fala - principalmente porque o foco narrativo também varia constantemente -, num processo lúdico que faz com que o leitor precise deduzir ou voltar e reler certos trechos para se certificar:

- Se estiver vivo um dia ele aparece, foi o que eu sempre disse.

- O que foi que o senhor disse?

Naquela hora eu podia fazer uma linha reta na minha cabeça até o sol e, como um macaco numa corda, subir por ela até Deus - eu, que nunca tinha precisado saber as horas (TORRES, 2005, p. 9).

Somente mais à frente desse trecho que inicia o romance é que se tem conhecimento de que o "eu", narrador em primeira pessoa, é Totonhim dialogando com um tio e o "ele", de quem se fala, é Nelo. Esse artifício de não se apresentar de imediato os personagens que participam dos episódios ressalta o anonimato deles, caracterizados que são por sua posição marginal na sociedade. Tal recurso, aliado às mudanças bruscas de tempo e espaço a cada capítulo, tende a provocar uma sensação de perda de referência no leitor, que parece ser lançado no meio de uma cena já em andamento, sentimento semelhante ao experimentado pelos personagens do romance, em constante busca por um lugar no mundo.

A desreferencialização e a ambiguidade, que predominam em diversos níveis da narrativa, também se fazem patentes desde o título, a começar pelo pronome demonstrativo "essa", como constata Vicentini (1998, p. 52): "Enquanto dêitico, ele é intermediário. Não indica um lugar muito próximo do interlocutor, que usa 'esta' neste caso, nem um lugar muito longe, quando o interlocutor, então, usaria 'aquela'. $\mathrm{O}$ que significa que pode ser tanto um quanto outro, num movimento cíclico.” Portanto, o próprio nome já anuncia a relativização do espaço na obra, que situa os personagens numa espécie de entrelugar, ao figurálos num estado de desterritorialização em relação ao sertão e de não pertencimento em relação à cidade grande.

Os títulos das quatro partes em que o livro é dividido - "Essa terra me chama", "Essa terra me enxota", "Essa terra me enlouquece" 
e "Essa terra me ama" - também têm um caráter ambíguo, pois, em cada um deles, a expressão "essa terra" pode referir-se tanto ao sertão quanto à cidade, uma vez que, na história, ambos os espaços resumem razões para a saída e para o retorno dos personagens. Os verbos que complementam essa expressão encerram um conjunto de ações e sentimentos contrastantes (chama $\mathrm{x}$ enxota e enlouquece $\mathrm{x}$ ama) e apontam o movimento pendular de ida e volta, que determina ciclicamente a miséria e a loucura a que os dois lugares entre os quais se dividem os personagens levam: Nelo, assim como a mãe e o pai, não consegue conquistar nada na cidade grande, nem materialmente, nem espiritualmente, do mesmo modo que não havia conseguido nada no campo.

\section{A ALTERNÂNCIA DE VOZES NA APRESENTAÇÃO TEMÁTICA}

No romance, a sensação de perda de referência provocada no leitor ainda é intensificada pelas mudanças de foco narrativo que ocorrem, às vezes, de um episódio para outro, inadvertidamente, sem que seja possível identificar, de imediato, a quem pertence a voz narrante. Essa terra é o relato de uma volta à casa desintegrada, que é articulado a partir de lembranças e lacunas por meio de várias vozes que ecoam na voz do narrador, a empreender uma dolorosa viagem ao mundo do passado dos personagens em sua luta contra a decadência e a miséria, seja na forma de tentativa de permanência na terra ou de busca por melhores oportunidades na cidade.

Ao mesmo tempo participante e observador, condição que lhe confere uma perspectiva privilegiada, o narrador Totonhim reconstrói o passado da família buscando reconstruir seu próprio passado, numa tentativa de compreender qual é o seu papel no seio desse grupo. Ele se comporta como um espectador das tragédias que se anunciam por meio dos outros personagens principais (o irmão, o pai e a mãe), não apenas de fora, mas, muitas vezes, fazendo uma sondagem - de modo avaliativo, colocando seus pensamentos, sentimentos e impressões à mostra - na profundidade da consciência deles e da sua própria, chegando a adquirir, em alguns momentos, uma onisciência incompatível com um narrador em primeira pessoa de uma narrativa tradicional. 
Segundo Genette (1979, p. 245), “o romance contemporâneo franqueou esse limite [mudança de pessoa] e não hesita em estabelecer entre narrador e personagem uma relação variável ou flutuante". Acompanhando essa tendência, Essa terra joga rotativamente com uma focalização múltipla, passando da consciência de Totonhim para a dos mais diversos personagens e recorrendo, em certos momentos, à onisciência de um narrador que participa da história. A perspectiva do protagonista se alterna com a visão dos fatos e com os sentimentos apresentados por outros personagens, não somente por meio do diálogo em discurso direto, mas também pelo uso do discurso indireto, do indireto livre ou pelo próprio papel de narrador cedido a eles. $\mathrm{O}$ discurso de Totonhim, como ponto de vista dominante, é interrompido, volta e meia, para que os outros personagens exponham suas perspectivas sobre determinados fatos ou assuntos e exprimam seus sentimentos e anseios. À visão do narrador-personagem, ao quadro que ele constrói a partir de sua memória, juntam-se outras visões, os quadros constituídos pelos relatos ou pelas percepções dos personagens que ele convoca ao seu próprio relato e que fragmentam a narrativa em diversas vozes.

No romance, os espaços do sertão e da cidade se constroem sempre em relação à percepção que os personagens têm e expressam, ao realizarem seus percursos a caminho do conhecimento de si mesmos e também do mundo circundante. A concepção do espaço é formada a partir das diferentes opiniões pronunciadas sobre ele - principalmente as de Totonhim, de Nelo, do pai e da mãe - e da categoria que assume na escala de valores desses personagens. A narrativa explora a multiplicidade de pontos de vista, ao centralizar a narração em um personagem que compartilha sua visão com o relato da visão dos outros personagens, por meio de suas lembranças, esboçando os contornos sociais do sertão e da cidade, a partir da peregrinação deles, em constante movimento e busca.

Bakhtin, em suas proposições teóricas em relação ao discurso romanesco, formula os princípios do chamado "dialogismo" em literatura. Em seu estudo sobre a obra de Dostoiévski, em que considera o discurso como veículo de ideologias e determinante na formação da imagem do personagem, observa que o romance com enfoque dialógico "não se constrói como o todo de uma consciência que assumiu, em forma objetificada, outras consciências, mas como o todo da interação 
entre várias consciências, dentre as quais nenhuma se converte definitivamente em objeto da outra" (BAKHTIN, 2005, p. 17). Essas consciências são "conviç̧ões ou pontos de vista acerca do mundo". Ou seja, os personagens focalizam o mesmo objeto de maneiras diferentes, do ponto de vista de suas próprias verdades. Desse modo, o dialogismo, não apenas no texto literário, mas na linguagem em geral, consiste em um "cruzamento e interseção de duas consciências, de dois pontos de vista, de duas avaliações" em torno de um mesmo tema (BAKHTIN, 2005, p. 212).

Para Bakhtin (2005, p. 64), a orientação dialógica é "a única que leva em conta a palavra do outro e é capaz de focalizá-la enquanto posição racional ou enquanto um outro ponto de vista". Nesse caso, outros personagens têm a possibilidade de trazer para o texto sua própria valoração da realidade social. Cada um deles pode funcionar como um ser autônomo, exprimindo sua própria mundividência, coincida ela ou não com a ideologia do narrador. Numa configuração dialógica de uma obra literária, a presença do "outro" se manifesta nitidamente, tanto no plano das ideias, com a expressão do conteúdo ideológico contido no discurso dos personagens (do eu e do outro), quanto no plano da estrutura aparente ou da linguagem - o que Bakhtin denomina "polifonia" -, quando a voz do narrador polemiza com uma ou várias outras vozes.

A composição de Essa terra apresenta um caráter dialógico e polifônico na medida em que os espaços contrastantes - sertão e cidade -, que constituem a ambientação do romance, só existem com base nos vários discursos que os constroem. Os fatos e temas privilegiados pelo romance e que se desenvolvem nesses dois espaços são apresentados a partir da alternância de foco narrativo, possibilitando uma visão multifacetada do conjunto.

Tomando a exploração, no romance, da passagem do pequeno espaço, o familiar ou espaço-refúgio do sertão, para o grande espaçoincógnita, amplo e desconhecido da cidade, constata-se que os personagens manifestam, a esse respeito, posicionamentos diversos. $\mathrm{O}$ pai tem uma maior identificação com o lugar de origem, demonstrando uma relação telúrica com esse ambiente, como se observa, por exemplo, na expressão do seu pensamento, por meio do discurso do narrador: "Sua escrita era outra e essa ele tinha orgulho de fazer bem: riscos amarronzados sobre a terra arada, a terra bonita e macia, generosa o 
ano inteiro, desde que Deus mandasse chuva o ano inteiro" (TORRES, 2005 , p. 68). Sua mudança para a cidade de Feira de Santana, que acarreta a perda do ofício e, consequentemente, o apagamento de sua identidade, dá-se por falta de alternativa, contra a sua vontade, devido à perda do pedaço de terra e da casa que possuía em Junco para donos de propriedades maiores. Tal circunstância coloca em foco o problema da tendência à monopolização da terra, do fenômeno do êxodo do pequeno agricultor que não dispõe da estrutura necessária para se manter no meio rural, mas que também não encontra na realidade urbana uma função adequada para as suas habilidades.

A mãe de Totonhim, assim como Nelo e os outros filhos, por sua vez, mostra-se adepta dos benefícios que acredita que a cidade pode proporcionar, assumindo seu inconformismo com o atraso do sertão e sua preferência por um estilo de vida mais moderno. Essa oposição de pensamento entre o pai e a mãe constata-se, por exemplo, no sentimento diverso que a lembrança do carro de boi, um dos símbolos do modo de vida rústico do sertão, desperta em cada um deles. O pai, concentrado em suas recordações no momento em que se despede da terra que perdera para ir para a cidade, evoca com nostalgia o meio de transporte intrinsecamente relacionado à sua história de vida, uma das referências da sua identidade e do qual sentia orgulho pela habilidade que tinha em produzi-lo: "E quando um carro de boi passava cantando pela estrada, ele sabia que em algum lugar alguém estava anunciando a sua fama de mestre carpina" (TORRES, 2005, p. 74). Já a mãe, com uma visão mais prática, demonstra um sentimento de rejeição ao lembrar-se do veículo, que, para ela, não tem nenhum significado afetivo, remetendo apenas às dificuldades da vida no campo:

- Não, mamãe. Estamos na rural da prefeitura.

- Ah, bom. Antes isso do que um carro de boi. Sabe de uma coisa? Eu não tenho saudade daquelas viagens nos carros de boi. Eram tão demoradas (TORRES, 2005, p. 151).

Nelo, diferentemente de quando era jovem e alimentava ilusões em relação à cidade, adquire uma visão desencantada desse espaço, após sua experiência fracassada em São Paulo. Todavia, ao retornar ao sertão, sente-se deslocado por perceber que aquele não é mais o lugar 
guardado em sua memória e que o passado não pode ser revivido. Não encontrando um lugar para si no mundo e, consequentemente, com sua identidade esfacelada, o personagem busca na morte a resolução para sua condição instável.

Totonhim desde cedo carrega uma percepção pessimista tanto do sertão, para o qual não prevê possibilidades de melhora, quanto da cidade grande, pensamento que é agravado ao testemunhar o fracasso dos sonhos do irmão e de outros seus conterrâneos que acreditaram nas promessas de prosperidade desse lugar. Com um posicionamento marcado pela indiferença, sem muita empatia pelo espaço sertanejo onde nasceu e sem expectativas quanto à vida urbana, Totonhim, após a mudança dos pais para Feira de Santana e a morte de Nelo, sentindose sem um ponto de referência no qual se apoiar, opta por ir para São Paulo, na tentativa de buscar uma identidade própria, desvencilhada da imagem de fracasso do irmão mais velho.

Desse modo, com a exposição das várias perspectivas e sentimentos acerca desses espaços que se opõem, o romance traz, em sua representação da realidade, o sertão e a cidade como conjunturas sociais que acolhem e rejeitam os personagens, imbuídos, por essa razão, de uma atitude carregada de ambiguidade, oscilando entre o fascínio e o repúdio por esses ambientes. O espaço em Essa terra, tanto da cidade quanto do sertão, alterna-se entre a elevação e o rebaixamento, entre a descrição entusiasmada das características e possibilidades da nova terra em que a cidade se configura e a desesperança com a aspereza desse lugar, conforme o olhar a partir do qual o narrador direciona o discurso, mostrando ora o ponto de vista de um, ora o de outro personagem.

Apesar do caráter polifônico do romance, do entrelaçamento de perspectivas que expõem os variados posicionamentos em relação à questão do espaço associado ao problema da luta pela ascensão, os protagonistas tendem ao isolamento físico, ao distanciamento uns dos outros, raramente interagindo entre si, o que reforça o retrato de uma família desagregada. No começo da trama, os personagens vivem distantes entre si e só reúnem-se por circunstância da morte de Nelo, logo em seguida se separando novamente. O próprio espaço principal em que se desenvolve a trama, o sertão de Junco, por sua localização geográfica, configura-se como um lugar isolado em relação ao restante do país, conforme a descrição feita por Totonhim, um "fim de mundo" 
por onde nem Lampião nem Antônio Conselheiro tiveram coragem de passar.

Mais marcante do que o afastamento físico, no romance, parece ser o isolamento mental dos personagens, que permanecem encerrados em si mesmos. Mesmo com a diversidade de vozes que instaura a pluralidade de opiniões sobre os percalços comuns a todos eles, seus discursos mantêm-se represados em suas consciências, desenvolvemse no interior de seus pensamentos e raramente são exteriorizados e debatidos por meio do diálogo. Mesmo quando estão próximos, parecem ignorar o que se passa com o outro, cada um sofrendo em silêncio, como se o vácuo entre eles agisse à maneira de um isolante que permite que os atritos familiares sejam amortecidos. Esse problema da incomunicabilidade projeta-se na relativa "independência" das quatro partes do livro, dedicadas a cada um dos personagens principais, que parecem apresentar-se como unidades narrativas autônomas, característica intensificada pela falta de sequência temporal com que são ordenadas.

Embora tenham uma consciência independente, isolada - que não procura tomar conhecimento ou não leva em consideração a opinião do outro -, e pontos de vista às vezes divergentes entre si, o que se observa de comum ao longo da trajetória e do relato desses personagens é o fato de não conseguirem uma situação mais confortável, que os salve ou sequer altere seus destinos. Sem certezas a respeito do que fazem no mundo, por meio de suas perspectivas próprias questionam sua condição, que reflete a situação geral do sertanejo retirante, vagando num universo sem saída possível, presos a um contexto ríspido e indiferente às suas angústias existenciais.

\section{CONSIDERAÇÕES FINAIS}

A fragmentação da continuidade temporal da história, a relativização do espaço e a variação de perspectiva, geralmente realizadas de forma abrupta, auxiliam na composição da atmosfera caótica que perpassa o romance Essa terra, além de provocar a sensação de perda de referência no leitor, do qual é exigida uma postura participativa, no esforço de organizar de modo coeso os componentes 
narrativos. Essa ausência de referentes textuais sólidos, responsável por gerar insegurança e incertezas no leitor, acaba por refletir a situação dos personagens em relação à sua posição instável num mundo onde não há lugar para eles, oscilando entre a vida no espaço sertanejo do qual foram destituídos e uma estrutura social urbana na qual não estão completamente integrados.

Anatol Rosenfeld aponta essa tendência de se expressar por meio da forma o conteúdo histórico-social, ao afirmar que, na arte moderna, exprime-se "uma nova visão do homem e da realidade ou, melhor, a tentativa de redefinir a situação do homem e do indivíduo, tentativa que se revela no próprio esforço de assimilar, na estrutura da obra de arte, a precariedade da posição do indivíduo no mundo moderno" (ROSENFELD, 1996, p. 97). Com base nessas colocações, é possível constatar que as manifestações estéticas da modernidade descritas no ensaio de Rosenfeld, como as indefinições e instabilidades de categorias formais, são caracterizadoras da crise que ganha caráter permanente no romance de Antônio Torres, cujos procedimentos anunciam o "desabrigo" do homem, em meio à relativização generalizada de formas e valores.

Os conflitos em Essa terra se desenvolvem com base na relativização do espaço, a partir da oposição e da alternância entre campo e cidade, apresentados de maneiras diversas, conforme a visão de cada personagem. Essa alternância espacial, por sua vez, deriva das várias instâncias memorialísticas, de recortes da história de vida dos integrantes da família de Totonhim, representados por inúmeras quebras, avanços e retornos temporais. Cada um desses personagens apresenta um posicionamento particular diante dos mesmos conflitos, revelando o modo particular como a tensão entre os dois espaços antagônicos influi na constituição de suas identidades. O olhar múltiplo presente no romance estabelece uma polêmica entre posições ideológicas, fazendo com que os temas abordados sejam tratados de modo complexo e aprofundado, sem a apresentação de uma posição conclusiva. $\mathrm{O}$ aspecto polifônico, ao promover a intensificação dos conflitos e criar inconstâncias e incertezas, enriquece a discussão das questões levantadas, num jogo cruzado de pontos de vista responsável por avivar a consciência reflexiva do leitor, instituindo um caráter aberto à obra, que assume sua função crítica de questionamento sobre o contexto histórico-social que representa. 
THE INSTABILITY IN THE FICTIONAL UNIVERSE OF ESSA TERRA, BY ANTÔNIO TORRES

\section{ABSTRACT}

The paper discusses the structural constitution of the novel Essa terra, by Antônio Torres, seeking to evidence theinconstancyof the narrativecategories oftime and space as a reflection of condition of deterritorialization of the characters and their consequent identity fragmentation. The studyalso seeks toshow howthe plurality ofvoices, responsible for thisrelativityspace-time, provides amultifaceted viewof thethemebroached - the migration -, giving an open form to work, without presenting a conclusive position about the issues high lighted,in order to stimulate the reader's reflection.

KeYwords: Antônio Torres, memory, space-time fragmentation, polyphony,identity.

LA INESTABILIDAD EN EL UNIVERSO DE FICCIÓN DE ESSA TERRA, DE ANTÔNIO TORRES

\section{RESUMEN}

El artículo analiza la composición formal de la novela Essa terra, de Antônio Torres, tratando de poner de relieve el carácter inestable de las categorías narrativas de tiempo y espacio, lo que refleja la condición de despojo de los personajes y su consecuente fragmentación de la identidad. El estudio también pretende mostrar cómo la pluralidad de voces, responsable de esta relativización del espacio-tiempo, permite una visión multifacética del tema seleccionado - la migración - proporcionando un carácter abierto a la obra, sin presentar una posición definitiva sobre las cuestiones planteadas, con el fin de estimular la reflexión del lector.

PALABRAS-ClAVE: Antônio Torres, memoria, fragmentación espacial y temporal, polifonía, identidad.

\section{Notas}

1. Tomachevski (1976) distingue fábula (o que se passou) de trama (o modo pelo qual o leitor toma conhecimento dos fatos). Segundo o autor, a trama é 
constituída pelo relacionamento dos personagens no início da leitura da obra literária, independentemente da ordem lógica dos acontecimentos; a fábula corresponde à temporalidade linear e cronológica dos fatos acontecidos.

\section{REFERÊNCIAS}

ARISTÓTELES. Poética. Trad. Eudoro de Souza. Lisboa: Guimarães \& Cia, 1951.

BAKHTIN, Mikhail. Problemas da poética de Dostoievski. Trad. Paulo Bezerra. Rio de Janeiro: Forense Universitária, 2005.

GENETTE, Gerard. Discurso da narrativa: ensaio de método. Trad. Fernando Cabral Martins. Lisboa: Arcádia, 1979.

MENDILOW, Adam Abraham. O tempo e o romance. Trad. Flávio Wolf. Porto Alegre: Globo, 1972.

ROSENFELD, Anatol. Reflexões sobre o romance moderno. In:

Texto/contexto: ensaios. 5. ed. São Paulo: Perspectiva, 1996. p. 75-97.

TOMACHEVSKI, Boris. Temática. In: et al. Teoria da literatura: formalistas russos. 3. ed. Trad. Ana Mariza Ribeiro Filipouski et al. Porto Alegre: Globo, 1976. p. 169-204.

TORRES, Antônio. Essa terra. 20. ed. Rio de Janeiro: Record, 2005. . Um cão uivando para a lua. 4. ed. Rio de Janeiro: Record, 2002.

VICENTINI, Albertina. O sertão e a literatura. Revista Sociedade e Cultura, v. 1. n. 1, 1998. p. 41-54. Disponível em:

$<$ http://www.revistas.ufg.br/index.php/fchf/article/view/1778/2139. $>$. Acesso em: 5 dez. 2016.

Submetido em 26 de março de 2017

Aceito em 3 de junho de 2017

Publicado em 31 de agosto de 2018 